\title{
Una ciudad para los niños: los espacios de diversión para la infancia en el Distrito Federal, 1928-1940 ${ }^{1}$
}

\section{A city for children: Entertainment Childhood Spaces in the Federal District, 1928-1940}

\author{
Uma cidade para crianças: espaços lúdicos da infância no Distrito Federal, 1928-1940
}

Daniela Lechuga Herrero ${ }^{1}$

\section{Resumen}

El objetivo de este artículo es analizar las transformaciones ubanas que dieron visibilidad a la infancia en el Distrito Federal entre 1931 y 1940. En ese sentido, se parte de que la capital de México experimentó una serie de cambios encabezados principalmente por publicistas y empresarios - que afectaron la movilidad de la infancia en el espacio urbano. Las fuentes hemerográficas y documentos de planificación urbana, permiten conocer las modificaciones propias de la ciudad y los nuevos espacios de diversión a los que los menores tuvieron acceso, tales como los parques, cines, teatros, jugueterías y tiendas departamentales. La mayor aportación de este trabajo es que contribuye a problematizar si esos cambios urbanos impactaron a todos los niños, o si sólo estuvieron enfocados en los niños de la creciente clase media de la ciudad.

Palabra clave: Diversiones; Infancia; Ciudad.

\begin{abstract}
The objective of this article is to analyze the urban transformations that gave visibility to childhood in the Federal District between 1928 and 1940. In this sense, it is assumed that the capital of Mexico underwent a series of changes - led mainly by publicist and entrepreneurs - that affected the mobility of children in urban space. The hemerographic sources and urban planning documents allow us to know the changes inherent to the city and the new entertainment spaces to which minors had access, such as parks, cinemas, theaters, toy stores and department stores. The main contribution of this work is that it contributes to problematize if these urban changes impacted all children, or if they were only focused on children from the growing urban middle class. Keywords: Entertainment; Childhood; City.
\end{abstract}

\section{Resumo}

O objetivo deste artigo é analisar as transfomações urbanas que deram visibilidade à infância no Distrito Federal entre 1931 e 1940. Nesse sentido, pressupõe-se que a capital do México passou por uma série de transformações - lideradas principalmente por publicitários e empresarios — que afetaram a mobilidade das crianças no espaço urbano. As fontes hemerográficas e os documentos de planejamento urbano permitem conhecer as mudanças inerentes à cidade e os novos espaços de diversão aos quais os menores tiveram acesso, como parques, cinemas, teatros, lojas de brinquedos e lojas de departamentos. A maior contribuição deste trabalho é que ele contribui para problematizar se essas mudanças urbanas impactaram todas as crianças, ou se foram focadas apenas nas crianças da crescente classe média da cidade.

Palavras-chave: Diversão; Crianças; Cidade.

${ }^{1}$ Doctorante en Historia en El Colegio de México. México. E-mail: dlechuga@colmex.mx | https://orcid.org/00000003-3483-9755 
El Distrito Federal fue el laboratorio de implementación de las políticas públicas en torno a la infancia. Por lo tanto, los niños fueron tomados en cuenta - al menos desde el ámbito discursivo - por el Estado mexicano después de la revolución. Al mismo tiempo, la década de los treinta representó la consolidación de la transformación de los espacios urbanos de la ciudad. Específicamente, se buscó dar funcionalidad al centro político del país y enlazar a la municipalidad de México con las periferias.

Se ha estudiado a la ciudad a partir de distintas perspectivas historiográficas que tienen que ver con el ámbito político, urbano y social. En lo que respecta a este texto, es importante recuperar los estudios que se concentran en los sujetos que habitaron la metrópoli a inicios del siglo XX. Por ejemplo, la presencia de los trabajadores ha tenido un lugar importante para comprender los espacios urbanos. Incluso, se les ha abordado a partir de la presencia infantil. ${ }^{2}$ A través de esta historiografía, ha quedado claro que la calle era el lugar de encuentro de un sinfín de actores que llevaban a cabo distintas actividades. ${ }^{3}$

Finalmente, los estudios urbanos de las primeras décadas del siglo XX se han enfocado en la Ciudad de México al ser el espacio del Distrito Federal (DF) que tenía mayor importancia política y urbana. En esta municipalidad se centralizaron las políticas públicas. El espacio público fue el foco de discusiones con respecto a cómo se debían de comportar las personas y los lugares que tenía que ocupar cada uno de los sectores sociales.

Así, este texto se centrará en un aspecto que no ha sido abordado con anterioridad por la historiografía: las transformaciones urbanas que dieron visibilidad a la infancia en el DF entre 1928 y 1940. Por lo tanto, la hipótesis central es que el DF experimentó una serie de cambios encabezados principalmente por los publicistas y empresarios - que afectaron la movilidad de la infancia en el espacio urbano. Los distintos barrios y colonias que conformaban a la capital mexicana se modificaron para mejorar la circulación, lograr una buena ocupación de viviendas y enlazar la periferia con el centro. Estos cambios transformaron, como un efecto secundario, la forma en que los niños utilizaron su tiempo libre. Los menores tuvieron acceso a nuevos espacios de diversión: en la ciudad, asistieron a los parques; conocieron nuevas opciones de entretenimiento con los cines y teatros; y visitaron las jugueterías y tiendas departamentales que eran parte de una renovada infraestructura para el consumo. 
Especialmente, estos nuevos espacios de diversión, como se verá a lo largo de estas páginas, fueron frecuentados por los niños de clase media. ${ }^{4}$ En ese sentido, es importante mencionar que en este trabajo se entiende que ese sector de la sociedad infantil se puede caracterizar como un grupo que creció enmarcado en la mediación institucional del Estado en diferentes dimensiones: higiene, educación y recreación. Igualmente, los niños de clase media formaron parte de una época de transformaciones urbanas que implicaron una serie de cambios en la infraestructura escolar, elemento fundamental en su desarrollo. ${ }^{5}$

Este texto se estructura en tres apartados. En primer lugar, ahondo en algunos aspectos del Distrito Federal en cuanto a su composición política y administrativa como "corazón del proyecto nacional" después de la revolución, recuperando ciertos elementos de la planeación urbana en la época. En el mismo apartado, explico la importancia que tuvieron los parques como espacios ideales para la sana recreación de los menores. Después, me concentro en las jugueterías en tanto espacios que se hicieron accesibles para los niños consumidores y su ubicación espacial. Finalmente, presento la distribución de los cines y teatros más importantes en el DF y qué se esperaba de estos lugares como espacios de diversión para los niños.

\section{Trazos de un sueño: el proyecto nacional, la planificación urbana y los parques}

En la segunda década del siglo XX, el DF reafirmó su vocación histórica como "corazón del proyecto nacional". ${ }^{6}$ Desde aquí, los poderes federales discutieron el destino del país. Sin embargo, existieron retos para gobernar en un espacio con sus propios problemas y disputas locales. Aunque no de manera central, los niños fueron parte de estos debates con relación a la ciudad.

A partir de ese momento, la capital siguió teniendo relevancia política y social. Las múltiples opciones laborales que tenía el DF, específicamente la Ciudad de México, motivaron la migración — sobre todo de estados aledaños como el de México, Hidalgo, Morelos y otros — con la idea de conseguir trabajo y mejorar las condiciones de vida. ${ }^{7}$ Por esta razón, en esta época hubo un reacomodo de grupos sociales en el DF. Así, se construyeron nuevas colonias para las élites y, también, para los sectores populares que tomaron espacios al oriente. Las clases medias encontraron cabida en los fraccionamientos de la periferia que hasta entonces se veía como alejada del centro. ${ }^{8}$

Según Regina Hernández Franyuti, en la primera década del siglo XX y durante el gobierno de Álvaro Obregón (1920-1924), el proceso de crecimiento urbano provocó dos fenómenos: la 
expulsión de la población de la Ciudad de México hacia las distintas municipalidades, por un lado, y, por el otro, atrajo la migración hacia la ciudad. No obstante, uno de los conflictos más importantes a raíz de esto fue la falta de servicios urbanos, lo que fue considerado por el poder federal como una falla en la administración del ayuntamiento (HERNÁNDEZ, 2008, p. 178). El problema ocurría porque además de la migración proveniente de otros estados hacia la capital, los movimientos al interior del DF fueron parte de la reconfiguración de su territorio y de las disputas entre las autoridades por la provisión de servicios.

La mayor parte de los asentamientos se ubicaron, como lo apunta Erica Berra Stoppa, en zonas que no contaban con infraestructura suficiente. En sus palabras, esto provocó el crecimiento desordenado de la urbe, lo que motivó el surgimiento de un nuevo tipo de capitalista: el fraccionador urbano. Este agente aprovechó la inexistencia de oferta de áreas urbanas y la presencia de una creciente demanda de casas habitación, o bien, de terrenos urbanos donde construir para especular sobre los bienes raíces (BERRA, 1982, p. IV).

Por ende, desde finales del siglo XIX la capital se configuró en un proceso de largo aliento. $\mathrm{Al}$ poniente, se establecieron los fraccionamientos residenciales $\mathrm{y}$, al sur, los de clase media y media baja. Al oriente y al norte se crearon las colonias para la clase obrera.

Y, en el mismo sentido, junto a un barrio obrero, la clase media construía colonias y fraccionamientos a la altura de sus expectativas. Segregación e interclasismo formaron así, en la ciudad de México, un abigarrado mosaico que escapa a fáciles determinaciones conceptuales o a la modelística clásica de la conformación urbana de otras experiencias nacionales (BERRA, 1982, p. V).

Berra Stopa retrata la presión social que se conjugó con la urgencia de las operaciones especulativas privadas. Según la autora, para inicios del siglo XX, el Estado fue incapaz de seguir el paso a las necesidades sociales, de imponer controles y orden a los intereses particulares, por lo que se generaron problemas urbanos que devinieron en conflictos como en el inquilinario de 1922. ${ }^{9}$

La reforma de 1928, en la que se eliminaba la figura política y territorial del municipio libre, fue importante porque el Distrito Federal se convirtió en una unidad administrativa que dependía del presidente. Los cambios políticos acompañaron los cambios urbanos y a partir de ese momento se procuró que las delegaciones estuvieran mejor articuladas, lo que implicaba, entre otras cuestiones, la transformación de las vialidades y del sistema de transporte.

En esta nueva reorganización administrativa se evidencia que el DF mantuvo un ejercicio autónomo sin coordinación con la Secretaría de Educación Pública ni con el Departamento de 
Salubridad Pública, con el fin de materializar, lo que, desde el discurso, se propugnaba a favor de la atención infantil.

Además de los reacomodos políticos que se vivieron durante la década de los veinte y treinta en el DF, el ámbito urbano se fue modificando paulatinamente. La planificación urbana surgió como una disciplina que poco a poco fue ganando terreno, ya que resultaba prioritario contribuir a lograr un espacio urbano funcional. De hecho, en 1926 se creó la Asociación Nacional para la Planificación de la República Mexicana (ANPRM), de la que el arquitecto Carlos Contreras fue dirigente. $^{10}$

Contreras fue uno de los personajes que soñó al Distrito Federal como un espacio urbano moderno, sano y ordenado. A pesar de que a través de distintas publicaciones, iniciativas y reuniones buscó propagar sus ideas, únicamente llevó a cabo la ampliación de la calle San Juan de Letrán entre 1933 y 1938. Su proyecto respondió a la necesidad de incorporar una mayor cantidad de automóviles. ${ }^{11}$ Contreras no sólo promovió los estudios de planificación urbana en México, sino que propuso estudiar los planos de las ciudades del país para mejorarlas. Su intención era que se crearan centros industriales, jardines públicos, parques, campos de juego y recreo en todas las ciudades. Asimismo, buscaba aplicar los principios de salubridad e higiene, por lo que cada casa debería de tener un jardín (ESCUDERO, 2004, p. 351). Así, la ANPRM, en una de sus editoriales, mencionaba:

Necesitamos crear mejores condiciones de vida, de descanso y de recreo para los habitantes de nuestras ciudades; mejores habitaciones; más parques y jardines; más campos de juego y de recreo; la división de las ciudades en zonas; la adecuada localización de ferrocarriles e industrias; mercados más amplios, más limpios y mejor ventilados, reglamentaciones y legislación adecuadas; sistemas más completos de drenaje y abastecimiento de aguas; más calles pavimentadas; la apertura y ensanchamiento de calles y arterias para formar un sistema circulatorio ligado entre sí por plazas y bulevares y vías-parque. Es urgente reglamentar todo esto, fijando alineamientos futuros [...] es necesario convencerse de que estas obras requieren siempre una o dos generaciones para verlas realizadas (ESCUDERO, 2004, pp. 351-352).

Por otro lado, Alejandrina Escudero sostiene que el incremento de los automóviles fue un factor decisivo para que, entre 1919 y 1928, el DF tuviera una paulatina e incesante actividad de pavimentación, ampliación y apertura de avenidas por varios rumbos, a cargo de la Secretaría de Comunicaciones y Obras Públicas (SCOP) como Chapultepec-Popotla, Mixcoac-San Ángel, San Ángel-Coyoacán, Contreras-Tlalpan, Santa Coleta-Puente de Aragón, México-Coyoacán, La Piedad-Tacubaya e Insurgentes (ESCUDERO, 2004, p. 362). ${ }^{12}$ 
A diferencia del interés por los espacios urbanos higiénicos y bellos a finales del siglo XIX, a inicios del siglo XX, la prioridad era que fueran funcionales y modernos. En específico, en los años treinta se consolidaron algunos cambios importantes: "en 1933, la ciudad de México sufrió una transformación que la prensa comparaba con la emprendida en el porfiriato, orquestada por dos políticos, Aarón Sáenz, jefe del Departamento del Distrito Federal, y Alberto J. Pani, secretario de Hacienda" (ESCUDERO, 2004, p. 367).

Planeadores urbanos como Miguel Ángel de Quevedo y Carlos Contreras, herederos de algunas tendencias del siglo XIX, imaginaban un espacio urbano conectado y complejo más allá de la Ciudad de México. Buscaban que el Distrito Federal fuera una entidad articulada, por lo que pensaban que la mayor parte de las modificaciones se llevaran a cabo en los espacios periféricos, dado que los centrales ya estaban ocupados con viviendas, comercios, centros de reunión y oficinas de gobierno. En El plano regulador, Contreras explicaba que "el Distrito Federal forma parte principal del Valle de México y constituye el núcleo poblado más importante de la República Mexicana. Al corazón del Distrito Federal llegan, y por él pasan, todas las vías - caminos, ferrocarriles y rutas aéreas - de mayor circulación en el país" (CONTRERAS, 1933, p. 10).

Sería el presidente Abelardo L. Rodríguez (1932-1934) quien apoyaría el plan regulador elaborado por Carlos Contreras para la Ciudad de México, así como las iniciativas de Miguel Ángel de Quevedo respecto a la creación de espacios abiertos y reservas forestales, respaldadas por el entonces gobernador del Distrito Federal, Aaron Sáenz (VALENZUELA, 2006, pp. 69-79). La ciudad estaba invirtiendo dinero en su transformación y, de acuerdo con el presidente de la república, se habían gastado recursos económicos en convertir a la capital en un espacio moderno: se reparaba el sistema de agua, el de atarjeas y se construían edificios nuevos.

Con respecto a la importancia que tuvieron los parques específicamente, el presidente informó que se habían invertido 75 mil pesos en nuevos parques y jardines para el DF, pero se habían empleado 150 mil sólo en el monumento y parque de La Bombilla, así como 140 mil en el monumento a la revolución. Por otra parte, las obras de pavimentación eran las que se llevaban gran parte de los bienes, pues se declaraba que se había invertido un millón de pesos en ellas. ${ }^{13}$ Evidentemente, la prioridad era que las calles de la metrópoli fueran adecuadas para la circulación de los automóviles. Asimismo, la preocupación de las autoridades era que el discurso de la 
revolución — en forma de monumentos — quedara a la vista de todos, más allá de procurar espacios pensados para los propios habitantes y mucho menos para los niños.

Con relación al interés por la circulación, Mario Barbosa ha explicado que en este sentido existía también un temor al enfrentamiento de las masas en las vías públicas. Por ello, los planificadores urbanos partían de la idea de que las aceras y calles sólo deberían ser ocupadas para la circulación de vehículos y transeúntes, para así, desplazar la vida social a los parques, jardines o al interior de las viviendas (BARBOSA, 2008, p. 57).

A este respecto, se discutía acerca de los esfuerzos gubernamentales por el embellecimiento de la ciudad, lo cual implicaba construir nuevos espacios para procurar el sano esparcimiento de la infancia. A pesar de que no fueron construidos para ellos, sino para la recreación de toda la población del DF, los niños tuvieron acceso a los parques. Igualmente, el aumento de población infantil fue detonante de una nueva cultura de consumo, la cual materializó nuevas rutas hacia lugares como las jugueterías, cines y teatros. Las jugueterías se ubicaron en el corazón de la urbe. Por otro lado, los cines y teatros fueron lugares que generaban muchas discusiones con respecto a la presencia infantil, pero que indiscutiblemente seguían atrayendo a los niños. ${ }^{14}$

La prioridad era darle una nueva imagen a la ciudad y procurar la visibilidad de los niños en lugares sanos. ${ }^{15}$ De acuerdo con esto, las discusiones con respecto a la sana recreación infantil aparecieron para modificar el espacio urbano. La intención de Contreras estaba alineada con los ideales de reconstrucción del país. El arquitecto pensaba en:

El cultivo y el desarrollo organizado en México de los medios de expresión y de expansión del cuerpo y del espíritu por medio de su música, sus cantos, sus bailes, sus juegos y artes, para lograr un medio ambiente más alegre más tranquilo y más nuestro, que nos asegure generaciones mejores, más sanas y más felices [El anhelo de la revolución] (CONTRERAS, 1933, p. 47).

En este sentido, Carlos Contreras argumentaba los logros que se alcanzarían por medio de la construcción de espacios como los campos de juego, deportivos, gimnasios, estanques, clubes de exploradores o lugares para acampar. Asimismo, proponía que esto se lograría a través de asociaciones recreativas, fomento al teatro, la música, el canto, el baile, los deportes, los juegos olímpicos, la educación física, social, higiénica y sanitaria, entre otros.

El arquitecto sí se interesó por el desplazamiento y la recreación de los niños en el espacio urbano. En la revista Planificación, de la que Contreras era editor, el ingeniero D. Martin Augusti explicaba que los niños no debían alejarse de la escuela más de 300 o 400 metros para encontrar 
lugares de recreo. De ahí que consideraba conveniente que éstos se ubicaran detrás de las casas, aumentando la profundidad de los patios y ajardinándolos (AUGUSTI, 1928, pp. 23-24). ${ }^{16}$

Para los niños que van a las escuelas, los sitios más ventajosos para juegos deben estar en relación directa con aquéllas, para que puedan alternar el ejercicio físico con el trabajo.

Se calcula como conveniente proporcionar una hectárea por cada mil niños, teniendo en cuenta que éstos necesitan dos veces más terreno que las niñas. ${ }^{17}$

Después de lo dicho vienen terrenos dedicados a deportes, que exigen espacios de cuatro a cinco hectáreas. Estos campos se repartirán de manera que no haya que recorrer más de 1,000 metros para llegar a ellos, con acceso fácil y vigilancia asegurada (AUGUSTI, 1928, pp. 23-24).

Los planeadores urbanos, según lo expresaron en la revista Planificación, soñaron con una ciudad en la que se contara con 158 hectáreas de parques y espacios libres distribuidos por los cuatro puntos cardinales y convenientemente enlazados por avenidas. Además de los parques que aparecieron como lugares ideales para los niños, es importante constatar que muchos de esos proyectos urbanos no fueron llevados a cabo.

A pesar de ello, resulta relevante identificar que espacios como los parques eran lugares pensados para los niños de clase media. Es más, como lo puntualiza Elena Jackson Albarrán, los espacios públicos contribuyeron a un rol más público de los niños, incrementando su visibilidad y su función como miembros de la comunidad nacional. La investigadora explica que la era industrial en el mundo marcó el comienzo de la transformación en los paisajes de la vida de los niños, a través de cambios en la arquitectura y la cultura material diseñados para regularlos y procurar su socialización (JACKSON, 2014, p. 46). Los parques públicos en la Ciudad de México sugirieron que el discurso temprano revolucionario acerca de los niños todavía los trataba como símbolos y como objeto de preocupación pública acerca de salud e higiene de la nación, más que como individuos con derechos (JACKSON, 2014, p. 47).

En el Plano 1, se presenta la Ciudad de México en 1928. Como se puede observar, muchos de los sitios que resultaban atractivos para los niños, como parques, jugueterías, cines y teatros, tendieron a permanecer en la zona central de la urbe. En las calles que rodearon la Alameda y la Plaza de la Constitución hacia el oriente, los comercios, los cines y los teatros se ubican uno tras otro, lo que hace pensar en que esta parte de la capital se "especializó", entre otros asuntos, en el comercio y diversión para los niños. Estas calles - y el transitar de un comercio a otro - dieron visibilidad a la infancia entre 1928 y 1940. 
Aunque cines o parques tenían presencia en otras partes del Distrito Federal, se puede visualizar una diferencia radical con respecto a los parques, jugueterías, cines y teatros entre la Ciudad de México y la periferia que se extiendía por los cuatro puntos cardinales. Parecería, a simple vista, que la vida más activa de la capital seguía concentrada en la parte central de la urbe. Esta distinción es importante en la medida en la que influirá en las experiencias de los niños.

Es importante mencionar que algunos de los parques a los que los menores tuvieron acceso, y que se observan en el Plano 1, se construyeron antes del siglo XX. Por ejemplo, la Alameda central (6) y el Bosque de Chapultepec (11). Ambos tienen una historia de larga data desde el siglo XVI. Sin embargo, el zoológico de Chapultepec (4) se inauguró en 1923, lo que significó la creación de un espacio diseñado especialmente para familias y niños que podían admirar a los animales. Por otra parte, el Parque de la Ciudadela (13) y la Alameda de Santa María la Ribera (16), inaugurados hacia finales del siglo XIX, experimentaron remodelaciones durante las primeras décadas después de la revolución, lo que favoreció la presencia de personas de distintos sectores sociales.

Al finalizar la década de los veinte, nuevos parques de grandes dimensiones fueron puestos a disposición de la población de la ciudad. En 1929, por ejemplo, se construyó el Parque Venustiano Carranza (16) en la delegación Iztacalco, al oriente del DF. Tres años después, en 1932, también en esta zona, se abrió el Parque Balbuena (3) como un proyecto para la población obrera y construido sobre terrenos de origen agrícola (VALENZUELA, 2006, p. 154). Ambos espacios tienen la peculiaridad, frente a los otros como el Parque México o España, que fueron construidos con el fin de atender a la población trabajadora que residía en esa parte de la metrópoli.

Este tipo de parques surgieron en el contexto de los cambios que se procuraron para la vivienda trabajadora. Las autoridades buscaron que los obreros se ubicaran en colonias que contaran con lugares de recreación al aire libre, servicios básicos, escuelas y bibliotecas. En este aspecto, es evidente que después de la revolución los sectores trabajadores ganaron visibilidad y se hicieron merecedores de espacios con los requerimientos higiénicos básicos. "La construcción de espacios destinados a desarrollar el uso productivo del tiempo libre de los trabajadores; por ejemplo, espacios para fines culturales, deportivos y bibliotecas" (OLSEN, 2004, p. 150). El Parque Balbuena, en ese sentido, abría sus puertas para que obreros y sus familias, pudieran divertirse y ejercitarse. 
Por otra parte, barrios de mayor tradición como Mixcoac, San Ángel y Coyoacán buscaron ser conectados con el centro de la metrópoli. Los parques formaron parte de esta estrategia. Así, sobre la fábrica ladrillera Nochebuena se creó el Parque Nochebuena (2) en 1930, aprovechando que muchos visitantes acudían a visitar los hoyos que dejaba la fábrica para preparar ladrillos, los cuales se llenaban de agua. ${ }^{18}$ En la misma zona, aunque más al sur, se construyó el parque de la Bombilla, el cual fue de mucha envergadura dado que en él se edificó el monumento a Álvaro Obregón. Del parque la Bombilla, se comentaba en La Prensa que:

De acuerdo con el programa de planificación que se ha trazado el Departamento del Distrito, ya se han emprendido diversas obras que traerán como consecuencia un mayor embellecimiento de la ciudad.

Una de esas obras será la reconstrucción de una glorieta, en la confluencia de la Avenida 20 de Noviembre y calles de Cuauhtemotzin, de acuerdo con un bellísimo proyecto que tiene el Departamento, añadiéndose a esas mejoras la construcción de un Parque Infantil en el parque de La Bombilla, con calzadas de la manera del Bosque de Chapultepec, bancos y alumbrado moderno. ${ }^{19}$

Plano 1 - Parques, jugueterías, teatros y cines en la Ciudad de México entre 1928 y 1940




Fronteiras - Revista Catarinense de História | https://periodicos.uffs.edu.br/index.php/FRCH/index ISSN 2238-9717 | n. 38, p. 189-219, jul.-dez./2021 | DOI: https://doi.org/10.29327/253484.1.38-12

Fuente: elaboración propia con información de: 1) El Universal (1921, 1934, 1935, 1937, 1938), 2) La Prensa (1936, 1940), 3) El Excélsior (1934, 1941) y El Nacional (1939).

También al sur, Los Viveros (18) fueron declarados parque nacional en 1938. Este proyecto de Miguel Ángel de Quevedo, junto con la calzada que hoy lleva su nombre, fueron pensados por este planeador urbano como uno de los pulmones más importantes de la ciudad. Igualmente, Los Viveros se convirtieron en un lugar de recreación.

Más hacia el oriente, se construyeron, uno a un costado del otro, parque Delta y parque Necaxa. El Parque Delta (14) abrió en 1928 y fue remodelado en 1940. Albergó los eventos más importantes del beisbol; de hecho, alojaba a la Liga Mexicana de Beisbol. Por otro lado, el Parque Necaxa (5), creado en 1930, fue uno de los espacios más relevantes del futbol en el DF. Ambos parques permiten entender que este tipo de lugares no siempre sirvieron para que los niños pudieran jugar, también se convirtieron en sitios donde, en familia, podían ver espectáculos deportivos, los cuales cada día cobraron mayor importancia en la capital. De este modo, el "hombre nuevo" también se edificaba a partir de los sitios y las actividades que realizaba, las cuales, por supuesto, implicaban el sano esparcimiento. ${ }^{20}$

Al sur de la Ciudad de México, también se crearon el Parque España (7) y el Parque México (15). Éstos fueron construidos con el propósito de ser un sitio de esparcimiento y encuentro familiar, aunque los dos tuvieron un sentido político, así como el de la Bombilla. El parque España, creado en 1921, fue elaborado para festejar el centenario de la consumación de la independencia. Ambos fueron pensados para ser ejemplo de la idea de modernidad que se pretendía para la ciudad. Caso similar es el del Parque Jesús Urueta (20), hoy Jardín Pushkin, que adquirió el nombre debido a que Álvaro Obregón quiso hacer un homenaje a este personaje.

La ubicación de los parques, mayoritariamente en la zona poniente y surponiente del DF, hace pensar que su construcción respondió a dos cuestiones que tienen que ver con un mismo objetivo: por un lado, se trata de parques cuyas dimensiones superan los que existían antes de estos años y, por otro, la mayoría de ellos se ubicaron en las nuevas colonias para clases altas y medias, si bien sólo el Balbuena se emplazó en la zona oriente que era poblada por sectores populares, quienes se asentaron de manera irregular. Además del funcionamiento que los parques debían tener con relación a la infancia, fueron construidos con el fin de que circulara el aire y los habitantes vivieran en condiciones benignas. 
De igual modo, existieron otras diferencias entre los parques construidos antes del siglo XX y los que formaron parte del proyecto posrevolucionario. Evidentemente, en los edificados en las primeras décadas de la revolución, los niños tuvieron mayor visibilidad y afluencia porque representaban el sitio ideal para el sano desarrollo de los menores, quienes debían de llevar actividades físicas a fin de ser fuertes, sanos y vigorosos, como se esperaba fueran los nuevos ciudadanos. Además, fueron espacios democratizadores porque permitieron la convivencia de diferentes estratos sociales. ${ }^{21}$

A consecuencia de la transformación de la ciudad, la visibilidad infantil cambió. Sin embargo, esas modificaciones sólo afectaron, en su mayoría, la vida de los niños de sectores medios, quienes formaron parte importante de los discursos alrededor de la construcción de parques. Los niños jugando en los lugares públicos higiénicos fueron parte de la imagen de la ciudad moderna y renovada. En cambio, los niños de sectores populares se movían por la ciudad sin tener un lugar en concreto a donde acudir, por lo que se puede considerar que circulaban de manera más errática, pues sus objetivos, sobre todo el hacerse de recursos para subsistir, cumplieron otros patrones. ${ }^{22}$

La importancia del nuevo diseño del espacio urbano - más allá de los niños - radicaba en que sí se presentó la imagen de una capital moderna. Se trataba de la representación material del triunfo de la revolución mexicana. No en vano, en 1936 se terminó de construir el monumento a la revolución, el cual aparecía a la vista de todos como un verdadero triunfo. Los cambios en la ciudad fueron parte del proceso de consolidación de una nueva identidad, aunque se olvidara gran parte de lo que el arquitecto Contreras planteaba.

Evidentemente, la planeación urbana estuvo relacionada con lo que desde el discurso y las instituciones pretendió el proyecto nacional posrevolucionario. Como se ha afirmado en este trabajo, un "hombre nuevo" debería de consolidar los ideales de la revolución. Igualmente, en el espacio se proyectaron estos propósitos.

\section{El encanto de los niños: las jugueterías}

Los publicistas hacían alusión a los niños en los mensajes de las jugueterías. Estos avisos estaban presentes sobre todo en el mes de enero, ${ }^{23}$ con el fin de asegurar ventas para el día de reyes. Así, en los primeros días del año se incrementaba la publicidad de juguetes en los periódicos de 
mayor circulación a nivel nacional. En otras palabras, surgía un nuevo sector consumidor en la capital.

Todo apunta a que los niños se reconocieran a sí mismos como compradores potenciales, exigiendo a sus padres regalos a lo largo del año, sobre todo en el marco de las festividades. ${ }^{24}$ Este nuevo comportamiento infantil quedó plasmado en una caricatura del periódico El Universal, en la que se observa a dos niños que respondían a su madre, después de haber recibido su regalo de los Santos Reyes, que se trataba de "valiente porquería". ${ }^{25}$ Además, la escena llama la atención porque ambos niños - junto con un perro - se encontraban en la calle, afuera de lo que probablemente era un edificio de departamentos. Igualmente, es interesante porque los niños, aparentemente, estaban realizando travesuras e, incluso, golpeándose.

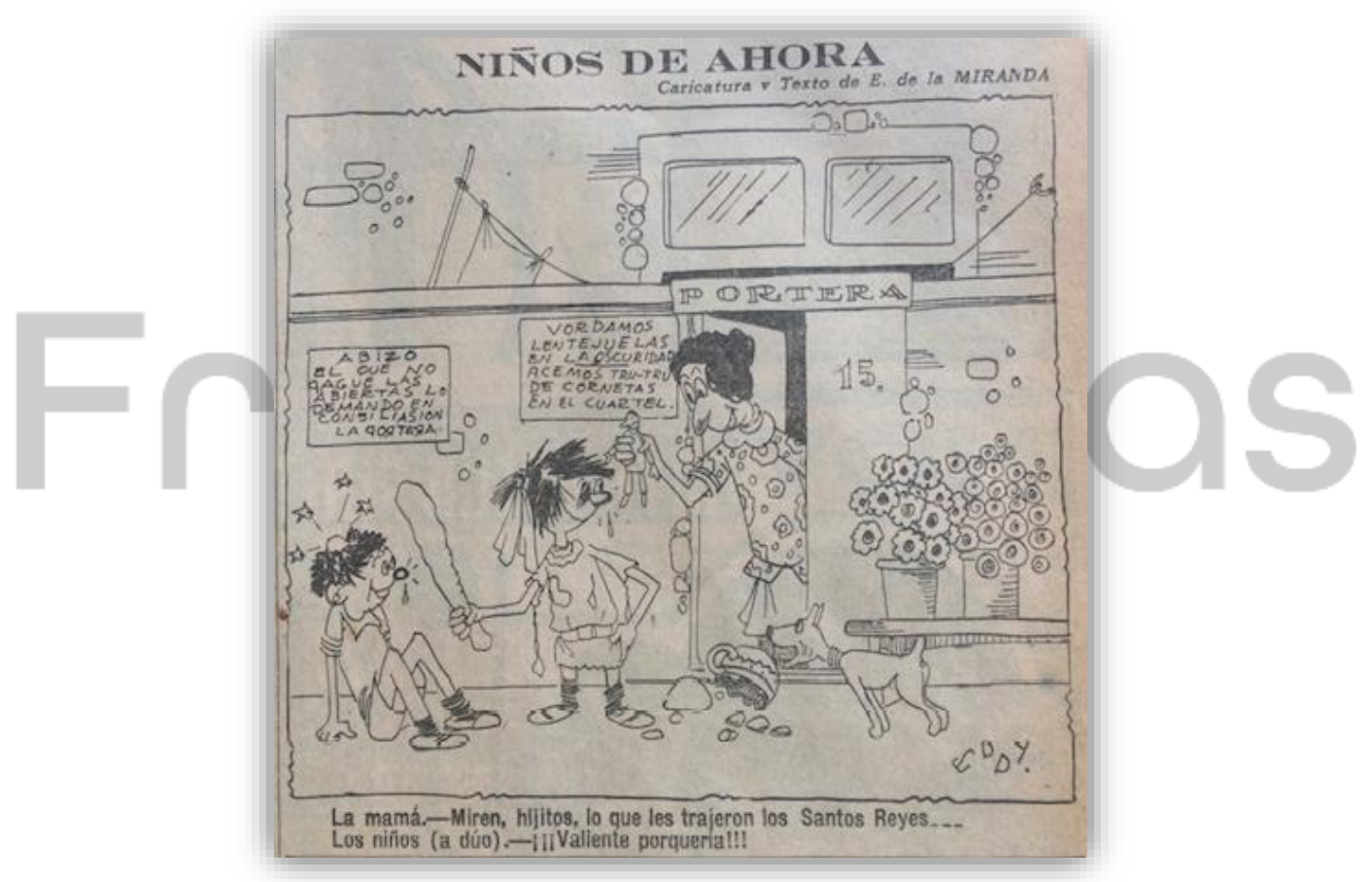

Fuente: "Niños de ahora", El Universal, 6 de enero de 1934, p. 5.

Como la historiografía lo ha puntualizado, el niño consumidor no irrumpió de la nada en México. Algunas investigaciones en Estados Unidos han rastreado la construcción de nuevas nociones de infancia en las primeras décadas del siglo XX, relacionadas específicamente con su capacidad de compra y con la nueva publicidad dirigida a ellos. ${ }^{26}$ Incluso, se ha reflexionado con respecto a cómo los espacios urbanos, particularmente en la ciudad de Nueva York, se 
transformaron a partir de las tiendas departamentales, generando así una nueva dinámica de movilidad de los niños. ${ }^{27}$

Según Peter Stearns, había una intención especial en incorporar a la clase trabajadora y a los niños en el nuevo sistema de consumo en Estados Unidos, de ahí que muchos de los lugares y artículos de esta época hayan sido diseñados para esta nueva práctica, como la aparición del Volkswagen en el caso de los trabajadores y, de juguetes como soldados y muñecas, en el caso de los niños. Al respecto, el autor menciona que el

consumismo ha sido asociado con la juventud y con la adultez joven, y de alguna manera eso continuó: esos fueron los grupos de edad más interesados en la novedad y a menudo fueron los más bendecidos con mayores ingresos disponibles. A pesar de ello, el consumismo también se extendió, como hemos visto, a la infancia e incluso a la lactancia (STEARNS, 2001, p. 51). ${ }^{28}$

Susana Sosenski ha analizado el tema para el caso mexicano. Entonces, puso atención en la construcción de la felicidad en los anuncios de prensa, donde se generó toda una nueva concepción de la familia y del papel que tenían en ella los espacios y el consumo para alcanzar la felicidad. Se configuraba por lo tanto una idea homogeneizada de la familia mexicana, la cual aludía a las clases media y alta (SOSENSKI, 2015, p. 199). Aunado a esto, aparecieron nuevos mensajes refiriendo a nuevos comportamientos de consumo infantiles e incitando la movilidad hacia estos lugares.

Así, la publicidad hizo eco de los discursos psicopedagógicos y si los manuales de cuidado de los hijos subrayaban que los niños debían estar rodeados de juguetes, la publicidad ofreció estos y otros muchos objetos. Si los niños debían jugar, también debían tener un espacio ideal para hacerlo. Los niños, representados como los hombres y mujeres del futuro, fueron entonces un gancho emotivo entre el consumidor adulto y las empresas de bienes raíces y fraccionadoras que proliferaban en México en ese periodo (SOSENSKI, 2015, p. 201).

Ya entrada la década de los treinta, se hacía alusión de los niños como compradores potenciales. ${ }^{29}$ En ese marco, surgían nuevas concepciones infantiles, las cuales, por supuesto, implicaban su ubicación en un ambiente específico: las jugueterías y las tiendas departamentales. Como se puede ver en el Plano 1, la Ciudad de México, específicamente en el corredor Alamedacentro, se conformaba como el espacio de consumo. Las jugueterías, cines y teatros, en su mayoría, permanecían concentrados en las calles más importantes del centro, alrededor de la Alameda central y la plaza de la Constitución.

Por su parte, el Plano 2 representa al DF en su totalidad para 1928. En él se pueden observar las divisiones territoriales-administrativas, por lo que se tiene una visión completa de los lugares 
infantiles por los que los niños de las primeras décadas después de la revolución se movían. Del mismo modo, se entiende que delegaciones como Milpa Alta, Tlalpan, Xochimilco o Tláhuac, al sur del DF, en realidad fueron muy poco consideradas como parte de la creación de nuevos lugares para la infancia, lo cual adquiere mayor sentido si se toma en cuenta que se trataba de terrenos rurales donde la mayor parte de la estructura urbana era deficiente.

Conseguir un juguete en el DF entre 1928 y 1940 no era fácil. Los niños de las periferias debían viajar hasta la Ciudad de México para recorrer las calles centrales de la capital y mirar en los aparadores. Por supuesto, los menores siempre iban acompañados por sus padres. Es importante tomar en consideración que, por ejemplo, "el recorrido suburbano de Xochimilco al centro de la ciudad tomaba entre 50 y 60 minutos, pero los trayectos de los viejos pueblos del sur, que prácticamente se habían conurbado con la municipalidad de México, como Mixcoac, San Ángel y el un poco más lejano Tlalpan, podrían hacerse entre 25 y 30 minutos" (COLLADO, 2003, p. 43). Además, al costo del transporte y a la inversión de tiempo, se tenía que agregar los precios de los juguetes, que no siempre eran accesibles (Ver tabla 1), lo que implica que eran sólo para los niños cuyas familias tenían ingresos que iban más allá de los niveles de subsistencia podían comprar un juguete. Sobre todo si se considera que el salario mínimo se estipuló entre 1.5 y 2.5 pesos diarios en el periodo de 1934 a $1940 .^{30}$

En este aspecto, es interesante notar que los juguetes que probablemente fueron más adquiridos, debido a su precio, son las pelotas de hule, las pistolas, los carritos y los ositos de peluche. A diferencia de las bicicletas, los juegos para construir, las muñecas o los aeroplanos que seguramente sólo pudieron ser adquiridos por pocos niños. Sin embargo, sí es notable que los precios abarcaron un rango amplio de posibilidades de compra. 
Fronteiras - Revista Catarinense de História | https://periodicos.uffs.edu.br/index.php/FRCH/index ISSN 2238-9717 | n. 38, p. 189-219, jul.-dez./2021 | DOI: https://doi.org/10.29327/253484.1.38-12

Plano 2 - Espacios abiertos a la infancia en el Distrito Federal entre 1928 y 1940

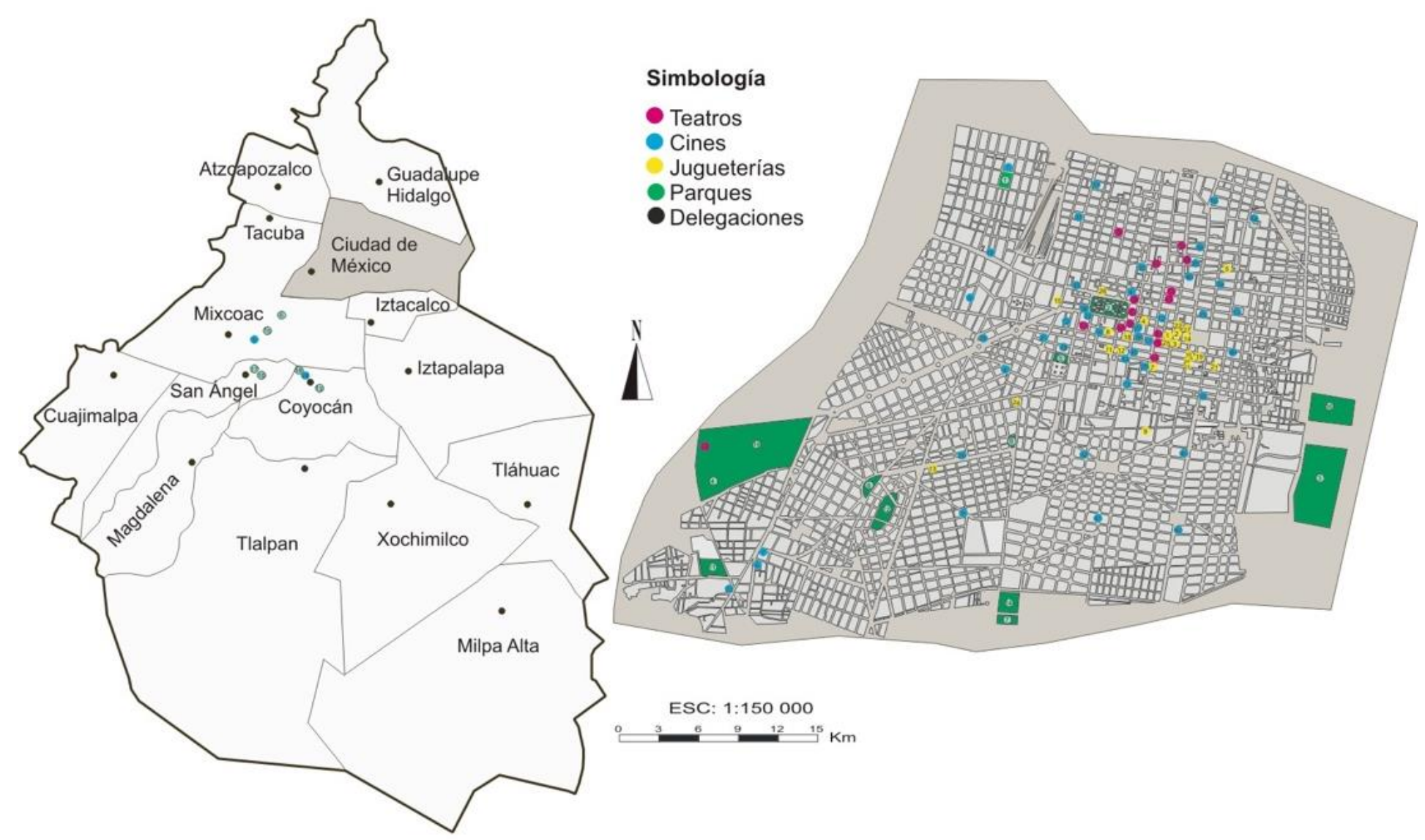

Fuentes: Mapa del Distrito Federal, 1928. Mapoteca Orozco y Berra. Clasif.: CGDF-V12-61-CGE-725-A; Mapa de la Ciudad de México, 1928. Mapoteca Orozco y Berra. Clasif.:1406-CGE-725-A-1 Datos del autor: Daniela Lechuga Herrero

Digitalizó: Felipe de Jesús Calderón Flores.

Fuente: elaboración propia con información de: 1) El Universal (1921, 1934, 1935, 1937, 1938), 2) La Prensa (1936, 1940), 3) El Excélsior (1934, 1941) y El Nacional (1939). 
La estratificación que se percibe a través de los precios de los juguetes también se puede visualizar a partir de la ubicación geográfica de las jugueterías, las cuales estuvieron ubicadas en las calles principales de la Ciudad de México, como 16 de septiembre, 20 de noviembre, 5 de mayo o 5 de febrero (Ver Plano 1), por lo que muy probablemente, sólo los niños de clases acomodadas podían acudir a ellas. Hasta sus vitrinas sólo iban los infantes que podrían - después de un recorrido desde los nuevos suburbios hacia la Ciudad de México - ir de la mano de sus padres y elegir un regalo. ${ }^{31}$

Tabla 1. Lista de precios de juguetes en la Ciudad de México, 1934-1940

\section{Tipo de Juguete Precio en pesos}

\begin{tabular}{cc}
\hline Bicicletas & $25-150$ \\
\hline Juegos para construir & $2-70$ \\
\hline Muñecas & $1-16$ \\
\hline Aeroplanos & $2.95-15$ \\
\hline $\begin{array}{c}\text { Juguetes para niñas (planchas eléctricas, } \\
\text { máquina de coser, estufa, vajillas) }\end{array}$ & $2.75-9.5$ \\
\hline Patines & $7.25-8.5$ \\
\hline Musicales (batería de jazz o piano) & $4.45-8.5$ \\
\hline Ferrocarriles & 4.5 \\
\hline Osito de peluche & 2.95 \\
\hline Carritos & 2.75 \\
\hline Pistolas & $1.5-2.1$ \\
\hline Pelota de hule & 1.2 \\
\hline
\end{tabular}

Fuente: elaboración propia con respecto a: 1) El Universal (1921, 1934, 1935, 1937, 1938), 2) La Prensa (1936, 1940), 3) El Excélsior (1934, 1941) y El Nacional (1939).

En algunas ocasiones, para hacerse de juguetes, los niños y sus familias podían acudir a tiendas departamentales como Sanborns, El Puerto de Veracruz, El Palacio de Hierro o El Puerto de Liverpool. También algunas pequeñas como El Jonuco, La Suiza, Casa Flor, Selecta o Abasco. Había también otras que, aunque no especializadas, igualmente vendían juguetes, como Ferretería San Juan, Mueblería Gift Granada Shop o Mercería Universal. Así como a las especializadas como la fábrica de vehículos infantiles Piranide. 
Como lo ha puntualizado Cristina Sánchez Parra, las tiendas departamentales más importantes continuaron ubicadas en el corazón de la Ciudad de México desde el siglo XIX. Los nuevos espacios de consumo, según la investigadora, evidenciaban un circuito de consumo que implicó una relación entre los compradores y las calles de la ciudad embellecidas por sus edificios imponentes (SÁNCHEZ, 2017, p. 13). En las tiendas departamentales, se encaminaba al consumo de lujo: la distribución de espacios, la luminosidad de las vitrinas y la disposición de las mercancías son todos elementos nuevos que modificaron la experiencia de compra, caracterizado, en el siglo XIX, con el flàneur francés (SÁNCHEZ, 2017, p. 15). Estos lugares llegaron a tener tanta relevancia en los sectores medios y altos en la metrópoli, que la autora recupera un testimonio del incendio de El Palacio de Hierro en 1914:

El Palacio de Hierro era el corazón de la ciudad de México que ardía de noche [...] Allí se confeccionaban las suntuosas vestiduras de las esposas de los próceres; allí había tocados con que soñaban las queridas de algunos ministros; allí había vestidos de novias; allí había pan para muchos diligentes servidores de la casa; allí había cristales que encerraban los "Bibelots" de París; allí había espejos; allí había luz; allí había esperanza [...] (SÁNCHEZ, 2017, p. 231).

Por otro lado, esos espacios de consumo se convirtieron en un lugar de recreación infantil. Tal es el caso del Puerto de Liverpool, a donde se invitaba a los padres a que acudieran con los niños a la inauguración de las primeras escaleras eléctricas del país. En el anuncio se puede observar a familias elegantemente vestidas. Los niños, tomados de la mano de sus padres, ocupaban el lugar central de la imagen. Indudablemente, era el tipo de lugar al que los niños de sectores medios acudían, según lo indicaba la prensa.

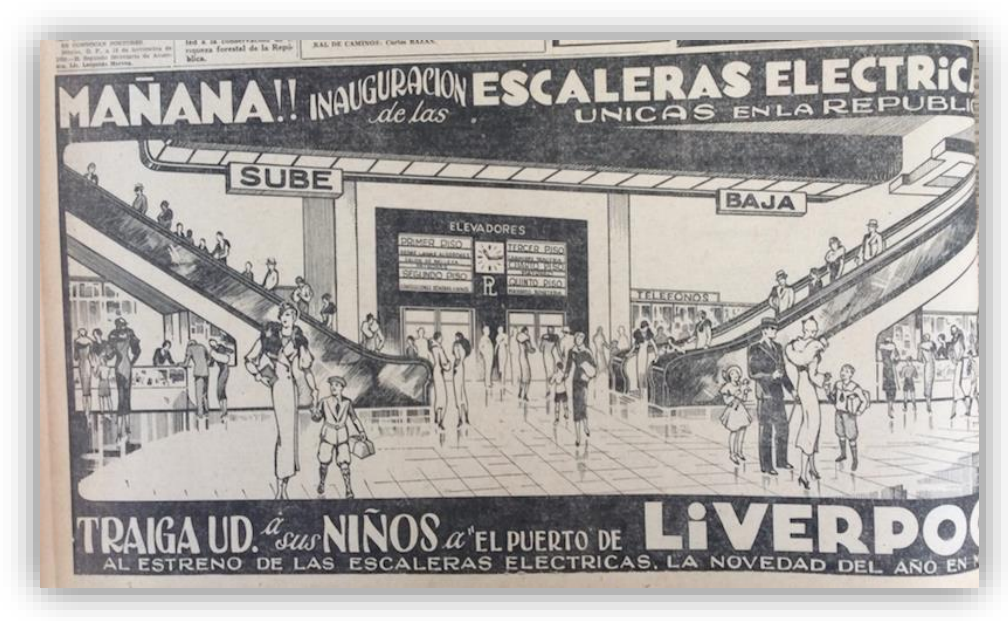

Fuente: “Inauguración escaleras eléctricas”, El Universal, 6 de diciembre de 1935, sec. 2, p. 6. 
Igualmente, se invitaba a los niños a que acudieran a la "Exposición de juguetes", la cual prometía ser "la mejor que se ha visto en México". ${ }^{32}$ En el anuncio se observaba la imagen de diferentes artículos como muñecas, ferrocarriles eléctricos, pistolas, automóviles, bicicletas, tiros al blanco, entre otros, lo que aseguraba a los lectores un gran momento de diversión. Las bicicletas, en especial, fueron promocionadas como el juguete predilecto para los niños. Por ello tuvieron un apartado especial en el Aviso Oportuno del periódico El Universal, en el que se podían leer anuncios de este tipo: "Bicicletas para niños desde $\$ 25$, hasta $\$ 110$ y juguetes baratos. La Hispano Germana. Serdán 29". ${ }^{33}$

Como se puede ver en el Plano 2, el consumo transformó la forma en la que los niños se movían por la metrópoli. La Ciudad de México continuó siendo el sitio de reunión para los pequeños que podían adquirir un juguete. Lo mismo ocurrió, en su mayoría, para quienes acudieron a espacios como los cines y teatros en busca de diversión.

\section{Las diversiones más deseadas: cines y teatros}

El DF era también un lugar para el ocio. Este aspecto en la vida de los capitalinos haría converger distintos intereses, particularmente estatales y comerciales. En ese sentido, a través del cine, pero sobre todo del teatro, el Estado buscaba incorporar nuevos valores en la población.

Con relación a esto, Tatiana Candelario explica que debido a la estabilidad económica que se vivió en la década de los treinta, existió una gama de actividades recreativas, siendo las más representativas el cine, radio, teatro y deportes. Entre los objetivos más claros de los gobiernos posrevolucionarios estaba educar a la población y, por lo tanto, poder alcanzar a más sectores sociales. Igualmente, a través de estas diversiones, según la autora, existió la intención de formar nuevos ciudadanos, por medio de la difusión y reafirmación de ciertos valores morales e ideales revolucionarios (CANDELARIO, 2010, p. 1).

A pesar de que el objetivo era que más personas acudieran al teatro, no todos los habitantes lo visitaban. Una de las iniciativas más importantes fue la del teatro guiñol, ${ }^{34}$ diseñada por la SEP. Esta estrategia fue peculiar porque se trataba de un proyecto cultural itinerante centrado en la niñez durante la década de los treinta (JACKSON, 2014, p. 177). Así como ocurría con los diversos monumentos, los cuales permitían que los espacios urbanos materializaran el discurso revolucionario, el teatro - para niños y adultos — sirvió como una forma de crear una identidad nacional. Elena Jackson Albarrán describe cómo el teatro tuvo que cambiar para poder llegar a los 
diferentes puntos de la ciudad, lo cual implicó que se simplificaran los títeres y escenarios para facilitar su transportación (JACKSON, 2014, p. 178).

Como se puede ver en los Planos 1 y 2 , los teatros no fueron construidos a lo largo de todo el Distrito Federal. Existían pocos comparados con los cines, los cuales de por sí tampoco alcanzaban todos los puntos de la urbe. Por ello, las carpas itinerantes, como se presentaba el teatro guiñol, fueron el mejor medio para llegar a los distintos puntos de la urbe. ${ }^{35}$ De ahí que muchos niños pudieron tener acceso, por ejemplo, a funciones como la de Comino vence al Diablo (JACKSON, 2014, p. 176). Así, las diversiones en las carpas estuvieron hechas para quien vivía en las periferias.

En los teatros establecidos y de mayor importancia, se presentaban obras generalmente dirigidas a los adultos. Muy pocas eran pensadas para los niños, como Pinocho, que llegaba al Arbeu, como se anunciaba en El Universal, para que "todos los niños de la Metrópoli estén que bailan de contento, porque podrán asistir en la función de esta tarde, al nacimiento de 'PINOCHITO'". ${ }^{36}$ No obstante, las obras infantiles ya eran parte de los espectáculos a los que los padres llevaban a sus hijos. Al respecto de Pinocho, el periódico describía "las aventuras que regocijarán a la gente menuda en esta segunda obra de teatro infantil que ofrecerá la Compañía Díaz-Collado, superan en emoción e interés a las ya conocidas, porque todas ellas se realizan en el fondo del mar, para que así tengan mayor fantasía y encanto para las imaginaciones de los espectadores". ${ }^{37}$

En algunas ocasiones, los habitantes de las periferias podían acudir a los teatros de la Ciudad de México. Eduardo Flores Clair describe que, por ejemplo, al teatro Esperanza Iris asistían grandes contingentes de personas de las orillas de la ciudad, por lo cual la compañía de teatro ofrecía tranvías nocturnos con el fin de transportar sin calamidades a su clientela. En el sur, el teatro Hidalgo era preferido por los habitantes, pues se llevaban a cabo representaciones dramáticas clásicas y algunas veces proyecciones de cine (FLORES, 1992, p. 163). ${ }^{38}$

En cuanto a los cinemas, la postura en el gobierno y la prensa era contradictoria: se procuraba que los niños acudieran a sus funciones, pero también se condenaba su presencia ya que podían corromperse. ${ }^{39}$ Generalmente, estos lugares eran vistos como centros de vicio que podían convertir a los jóvenes en delincuentes. Como lo explica Jackson Albarrán, en 1935, los especialistas de la infancia recomendaban que los menores no entraran a cines, teatros, plazas de 
toros y arenas de lucha. En contraste con el teatro guiñol que se consideraba un recurso educativo que llegaba a las áreas rurales y al centro, y que era bien visto (JACKSON, 2014, p. 180).

A pesar de ello, las autoridades estudiaban el porqué de que los niños no acudieran más al cine. En una nota en el periódico El Universal, se hablaba de una encuesta que la oficina de estadística de la SEP había elaborado para conocer cuántos niños concurrían a los cines establecidos en el DF. Partían de una población total de 175000 alumnos inscritos en las escuelas y explicaba la nota: "Ahora bien, de 150,000 alumnos, no concurren al cine 38,887, por diversas causas: porque no hay cines en la localidad donde viven, por carecer de recursos sus padres para comprar boletos, por no tener quien los acompañe a la diversión, etc., etc". ${ }^{40}$

Además de eso, algunos niños, según El Universal, explicaban que no acudían al cine por motivos de prohibición religiosa o ética. Sin embargo, el motivo principal era la falta de recursos: “18,564 alumnos manifestaron que no iban al cine, por que sus papás o mamás no tenían dinero". ${ }^{41}$ Una razón de más peso era también la falta de cines a lo largo del DF:

Como para hacer la encuesta se dividió la ciudad en Cuarteles, se sabe en la Secretaría cuál es la zona urbana en la que van menos número de niños al cine, siendo aquella la que comprende los barrios del Sur de la ciudad. Respecto de las Delegaciones: Xochimilco, Ixtapalapa e Ixtacalco, son las poblaciones que casi ningún niño concurre al cine, ocupando el primer lugar en esta clasificación, el florido Xochimilco.

Ahora bien, se considera que la asistencia de los niños al cine, contribuye a su desarrollo mental y por tanto la Secretaría, ya en posesión de los datos correspondientes, estudia desde ahora la manera de que, a partir del año entrante, la cifra de niños no asistentes al cine disminuya. En la zona Sur de la ciudad, desde Balbuena hasta Peralvillo, se atribuye la no asistencia al cine al hecho de que no hay cinematógrafos por esos rumbos. Lo propio sucede en Xochimilco, Ixtacalco, Ixtapalapa y Azcapotzalco. La Secretaría procurará que los niños concurran a los cines más cercanos, haciendo combinaciones con las empresas respectivas o bien construyendo salones de cinematógrafo en los lugares donde no haya. ${ }^{42}$

En el Plano 2, se presenta la ubicación de los cines cuya distribución abarca los distintos puntos de la ciudad. Los cines eran también lugar de consumo al que no todos los niños podían acudir. Como lo demuestra El Universal y la ubicación espacial de los cines en el DF, una de las razones era que no había suficientes a lo largo de la capital, pero también porque el precio de la entrada no era accesible para todos, ya que podía fluctuar entre 25 centavos hasta un peso. ${ }^{43}$ Por supuesto, una entrada al cine era más barata que comprar un juguete; sin embargo, de acuerdo al salario promedio, seguía siendo un lugar de difícil acceso para los sectores menos favorecidos. 
Empero, los propios medios impresos incentivaban la presencia de los infantes en este tipo de espectáculos. Por ello, construyeron estrategias de venta para asegurar la entrada al cine específicamente de los niños - a cambio de la compra del periódico, como se anunciaba en $\mathrm{La}$ Prensa: "Cada domingo sus niños podrían asistir a las matinées del Cine POLITEAMA, demostrando sus dotes de observación e ingenio. [...] Acostumbre a sus hijos a desarrollar las facultades de observación, tan útiles en la vida, y enséñeles usted lo que sabe. Vea nuestra edición dominical y haga que sus hijos concursen". ${ }^{44}$ Es claro que a pesar de las críticas que se hizo a la presencia infantil en los cines, desde el mundo de los negocios se procuró su asistencia como potenciales consumidores.

La cartelera de los cines, por lo general, no incluía películas para niños, lo cual se puede deber a que no había producciones propiamente infantiles. Los menores se escabullían, como algunos testimonios lo apuntan, a las salas de cine para ver las películas más famosas del momento, sobre todo hollywoodenses. Por lo tanto, eran clientes aunque no hubiera filmes dirigidos a ellos.

A pesar de ello, durante el periodo cardenista, el cine también estuvo envuelto en un halo de nacionalismo. Según Juan Pablo Silva Escobar, los valores que se difundieron a través de las películas mexicanas tuvieron la función de presentar estereotipos con los que se construía una nueva identidad y se procuraban nuevos comportamientos, los cuales estaban abocados al lenguaje, costumbres, prácticas culturales como en las relaciones de parentesco, la maternidad, el adulterio, el trato varonil, la belleza, entre otros. “Así, el cine de la Época de Oro ${ }^{45}$ participó en la elaboración de una identidad nacional y popular ayudando a consolidar elementos identitarios divulgados, en un primer momento, por la Revolución Mexicana y que, posteriormente, el cine volvió "típicos" y fácilmente imitables" (SILVA, 2011, pp. 20 y 21).

Niños y adultos acudían cada día más a ver películas estadounidenses, pero también mexicanas, así los teatros perdían importancia en aquellos años. ${ }^{46} \mathrm{Al}$ respecto, Julia Tuñón a puntualizado que existieron políticas que apoyaron la industria nacional, como "La semana de cine nacional" establecida en el mes de abril de 1939, en la que las salas de cine debían exhibir cine mexicano (TUÑóN, 1998, p. 58).

No obstante, las carteleras mostraban una mayor cantidad de películas americanas, con actores como Luise Rainer y Spencer Tracy en "La ciudad de acero", una historia de amor en la que se buscaba expulsar a la protagonista del país por un asesinato. Por otra parte, también se 
promocionaban películas en español como la protagonizada por Tito Guizar, "Amapola del camino", una comedia ranchera muy parecida al famoso film "Allá en el rancho grande". A medida que fueron avanzando los años, las películas mexicanas fueron más frecuentes, actores como Virginia Fábregas, Fernando Soler o Jorge Negrete estaban cada vez más presentes en las carteleras de la ciudad.

Las películas destinadas a los niños eran escasas, no obstante, se anunciaban en cartelera algunas como "Los tres cochinitos" presentada los días jueves en el cine Regis, u otras como "El niño elefante", la cual prometía ser muy distinta de lo que se había visto antes y que anunciaba a Sabu como el nuevo prodigio en 1937. Ninguna de las anteriores competía con la cantidad de anuncios que tenía "El hombre invisible" que, producida por Universal Pictures y con actores como Claude Rains, William Harrigan y Gloria Stuart, provocaba a las mujeres con la siguiente frase: "Suponga ud. Señorita, que estuviera enamorada de un hombre a quien pudiera oir y sentir sin poderlo ver. ¿Qué haría ud.?". ${ }^{47}$

Volviendo a la ubicación de estos espacios de diversión, como se puede ver en el Plano 1, la mayor parte de teatros seguía concentrada en la parte central de la capital. Es evidente que esto se pudo deber a que muchos de ellos tuvieron una larga tradición al estar asentados en edificios antiguos y, debido a su ubicación, también se puede inferir que al permanecer en las primeras calles del centro, pudieron estar dirigidos a sectores obreros. Incluso, se podría considerar que los teatros atendieron una demanda que no es instrumento del nuevo régimen, ni gusto de los nuevos sectores.

Los cines, de acuerdo con su localización espacial sí siguieron otra dinámica más acorde con el proyecto posrevolucionario, ya que quedaron dispersos en otras partes de la metrópoli. Prácticamente, abarcan los cuatro puntos cardinales, pese a que, como se puede ver en el Plano 2, existía una mayor oferta hacia el surponiente de la ciudad. Evidentemente, su ubicación seguía la trayectoria de los nuevos sectores emergentes.

Este elemento permitiría considerar que los cines y los parques probablemente fueron los lugares más visitados por los niños en el DF durante la época estudiada. Ambos sitios pudieron haber significado una forma más democrática de diversión infantil, a la que niños de diversos sectores acudieron y, en los que, en más o menor grado, debían consumir. Es decir, tanto en el cine como en el parque, los niños muy probablemente compraron dulces y algunos otros artículos que acompañaron sus momentos de ocio. 
Por otra parte, la ubicación espacial de los teatros, además de lo puntualizado anteriormente, facilita entender la importancia que tuvo el teatro guiñol en tanto proyecto educativo de los gobiernos posrevolucionarios. La movilidad que adquirieron las carpas facilitó que esta diversión alcanzara lugares más lejanos y traspasara las fronteras de Mixcoac, San Ángel y Coyoacán. En ese sentido, pudo haber sido el proyecto que más alcance tuvo y que más se acercó a la configuración de un nuevo mapa del DF desde la experiencia infantil.

\section{Consideraciones finales}

A través de estas líneas es evidente que, aunque se buscó transformar al Distrito Federal y procurar su funcionamiento de manera más articulada, la Ciudad de México siguió teniendo mayor importancia política y económica. En ese sentido, parece ser que la historiografía contemporánea ha tendido a enfocarse en ese espacio, pues evidentemente resulta esencial para comprender toda la dinámica del periodo en esta zona. Asimismo, sigue siendo central puesto que estuvo ocupada por oficinas, viviendas y comercios y, en ese sentido, continuó siendo el centro de consumo.

Según se apunta en estas páginas, las dificultades para articular el Distrito Federal como una unidad pueden deberse a las disputas políticas y administrativas que se dieron entre el presidente, el gobernador y los delegados. Sin embargo, llama la atención que sí logró consolidarse como centro político de los gobiernos posrevolucionarios con el presidente al mando del proyecto centralizador.

Con respecto a las transformaciones urbanas en esta zona del país, en efecto, los planeadores urbanos pusieron toda su atención en las zonas periféricas de la Ciudad de México. Sólo en las afueras del centro sería posible construir alternativas que permitieran un mejor funcionamiento de la urbe. Igualmente, los nuevos fraccionamientos, ubicados a las afueras de la metrópoli, fueron lugar de residencia de los sectores medios y altos emergentes.

Los publicistas y empresarios encontraron diversas maneras de hacer negocios a partir de los niños. Las autoridades, por su parte, más allá de los discursos en torno a la infancia, invirtieron gran parte de sus recursos en obras de pavimentación de las calles y, por supuesto, en materializar en el espacio urbano el triunfo de la revolución.

En las zonas periféricas de la Ciudad de México se construyeron la mayor parte de los parques en los que los niños tuvieron visibilidad. Estos espacios recreativos fueron construidos en 
su mayor parte en la zona poniente y sur poniente de la ciudad, justamente en áreas cercanas a los nuevos fraccionamientos. Cada uno de ellos tuvo sus particularidades: algunos surgieron para los obreros, otros para practicar o ver deportes, otros con intenciones políticas y otros donde los niños pudieron jugar.

Por otra parte, aunque la historiografía ha puntualizado que los años treinta podrían haber sido una coyuntura importante en la irrupción del niño consumidor, la ubicación geográfica de las jugueterías apunta a que fueron espacios dirigidos a unos pocos infantes. Las tiendas departamentales y las jugueterías continuaron ubicadas en la zona comercial tradicional de la Ciudad de México, por lo que los niños y sus padres, además de pagar por el juguete, tuvieron que invertir tiempo y dinero para trasladarse hacia esta zona.

Los teatros permanecieron ubicados en el centro de la urbe, lo cual cobra sentido si se considera que en su mayoría estuvieron establecidos en edificios antiguos. Del mismo modo, debido a su ubicación espacial, el público al que ofrecieron entretenimiento continuó siendo, en la mayor parte de los teatros, el de los obreros. En cambio, los cines sí se localizaron en distintos puntos del DF, siguiendo la lógica del crecimiento de nuevos asentamientos.

Los parques y el teatro guiñol - el cual fue presentado en las carpas itinerantes resultaron ser formas más democráticas de diversión. Tanto los parques como el proyecto educativo del teatro guiñol recorrieron una mayor parte del DF, lo que los convierte en la única posibilidad de su articulación, más allá de San Ángel, Mixcoac y Coyoacán que sí fueron una prioridad para los gobiernos posrevolucionarios.

Evidentemente, la movilidad y la visibilidad de los niños en el espacio público fue sectorizada. Los niños de clase media contaron con nuevos destinos como las jugueterías, los parques, los cines y los teatros en los que debieron consumir. Por tanto, a pesar de que no fueron el objetivo principal de las políticas públicas, los niños sí comenzaron a experimentar una ciudad más abierta para ellos.

\section{Referencias bibliográficas}

ABOITES, Luis; LOYO, Engracia. La construcción del nuevo Estado, 1920-1945. In: GARCIA, Erik Velásquez et al. Nueva historia general de México. El Colegio de México, México, 2011, pp. 595-649.

ALCUBIERRE MOYA, Beatriz. Ciudadanos del futuro: una historia de las publicaciones para niños en el siglo XIX mexicano. El Colegio de México/UAEM, México, 2010. 
Fronteiras - Revista Catarinense de História | https://periodicos.uffs.edu.br/index.php/FRCH/index ISSN 2238-9717 | n. 38, p. 189-219, jul.-dez./2021 | DOI: https://doi.org/10.29327/253484.1.38-12

ARÉCHIGA CÓRDOBA, Ernesto. De Tepito a la Merced: una revisión de la narrativa en torno a barrios marginales del centro de la Ciudad de México. In: DÁVALOS, Marcela (Coord.), Márgenes, barrios y suburbios en la Ciudad de México, siglos XVI-XXI, INAH, México, 2012, pp. 109-127.

ARÉCHIGA CÓRDOBA, Ernesto. La lucha de clases en la ciudad. La disputa por el espacio urbano, ca. 1890-1930. In: ILLADES, Carlos; BARBOSA, Mario. Los trabajadores en la ciudad de México 1860-1950. Textos en homenaje a Clara E. Lida. El Colegio de México, México, 2013. AUGUSTI, D. Martín. Parques Urbanos. In: Planificación, tomo 1, núm. 13, septiembre-diciembre de 1928, pp. 22-25.

ÁVILA CAMPOS, Fernando Vialli. La huelga de inquilinos de 1922 en la ciudad de México. Entre higiene, vecindades y protesta social. Tesis de licenciatura en Historia y Sociedad Contemporánea, UACM, México, 2017.

BARBOSA CRUZ, Mario. Distinciones y apariencias. La clase media en la Ciudad de México entre el porfiriato y la revolución. Oficio, revista de Historia e Interdisciplina, n. 10, enero-junio 2020, pp. 9-23.

BARBOSA CRUZ, Mario. El trabajo en las calles. Subsistencia y negociación política en la Ciudad de México a comienzos del siglo XX. México, El Colegio de México/ UAM-C, México, 2008.

BARBOSA CRUZ, Mario. Rumbos de comercio en las calles: fragmentación espacial en la Ciudad de México a comienzos del siglo XX. Revista electrónica de geografía y ciencias sociales, Barcelona, vol. X, núm. 218 (84), agosto 2018, pp. 1-11.

BAYARDO RODRÍGUEZ, Lilia Esthela. Entre el lujo, el deseo y la necesidad. Historia del gasto familiar y del consumo moderno en la Ciudad de México, 1909-1970. El Colegio de México, 2018. BERRA STOPPA, Erica, La expansión de la Ciudad de México y los conflictos urbanos, 19001930. Tesis de doctorado en historia, El Colegio de México, México, 1982.

BERRA STOPPA, Erica. ¡Estoy en huelga y no pago renta!. Habitación, Problemas de vivienda y urbanismo, año 1, núm. 1, enero-marzo de 1981, pp. 33-39.

CANDELARIO GALICIA, Tatiana Carolina. Diversión: educación y crítica. El teatro y su función social en la ciudad de México, 1930-1940. Tesis de maestría en Historia Moderna y Contemporánea, México, Instituto Mora, 2010.

CANTO MAYÉN, Emiliano. Automóviles y cultura vial en la Ciudad de México durante las décadas de 1910 y 1920, Boletín del Fideicomiso Archivos Plutarco Elías Calles y Fernando Torreblanca, núm. 78, enero-abril 2015, pp. 1-32.

CHAOUL PEREYRA, María Eugenia. Entre la esperanza de cambio y la continuidad de la vida. El espacio de las escuelas primarias nacionales en la Ciudad de México, 1891-1919. México: Instituto Mora, 2014.

COLLADO HERRERA, María del Carmen. Chapultepec Heights: un negocio urbano en la Ciudad de México posrevolucionaria. Antropología. Revista interdisciplinaria del INAH, núm. 72, 2003, pp. 42.51 (Empresas y empresarios).

CONTRERAS, Carlos. El plano regulador del Distrito Federal, México, 1933.

DE QUEVEDO, Miguel Ángel. Los espacios libres en las ciudades y su adaptación a parques, jardines y lugares de recreo. In: Planificación, tomo II, núm. 4, julio-semptiembre de 1934, pp. $24-$ 29.

DEL CASTILLO TRONCOSO, Alberto. Conceptos, imágenes y representaciones de la niñez en la ciudad de México, 1880-1920. El Colegio de México/Instituto Mora, México, 2006. 
Fronteiras - Revista Catarinense de História | https://periodicos.uffs.edu.br/index.php/FRCH/index

ISSN 2238-9717 | n. 38, p. 189-219, jul.-dez./2021 | DOI: https://doi.org/10.29327/253484.1.38-12

DURAND, Jorge. Huelga nacional de inquilinos: los antecedentes del movimiento urbano popular en México. In: Estudios Sociológicos, El Colegio de México/Centro de Estudios Sociológicos, vol. 7, núm. 19, 1989, pp. 61-78.

ESCUDERO, Alejandrina. Carlos Contreras, la planificación y la traza de la Ciudad de México, 1927-1938. In: COLLADO, María del Carmen (Coord.). Miradas recurrentes 1. La ciudad de México en los siglos XIX y XX, Instituto Mora/ UAM-A, México, 2004, pp. 349-375.

Estadísticas históricas de México, México, INEGI, 1999, tomo I.

FLORES CLAIR, Eduardo. Diversiones públicas en la Ciudad de México, 1920-1940. Historias. Revista de la Dirección de Estudios Históricos del Instituto Nacional de Antropología e Historia, núm. 27, octubre 1991-marzo 1992, pp. 163-170.

GRANT WOOD, Andrew. Urban Rebels: The Mexican tenant movement in the 1920s, en The Latin Americanist, vol. 54, núm. 4, 2010, pp. 121-142.

HARVEY, David. The contidion of posmodernity: an enquiry into all origins of cultural change. Massachusetts Blackwell, Cambridge, 1992.

HERNÁNDEZ FRANYUTI, Regina. El Distrito Federal: historia y vicisitudes de una invención, 1824-1995. Instituto Mora, México, 2008.

JACKSON ALBARRÁN, Elena. Seen and Heard in Mexico. Children and Revolutionary Nationalism. University of Nebraska, 2014.

LEACH, William R. Land of Desire: Merchants, Power, and the Rise of a New American Culture. Vintage Books, Nueva York,1994.

LECHUGA HERRERO, Daniela. Entre el ocio y el trabajo. La infancia popular en las calles de Ciudad de México en la década de 1930. Trashumante. Revista Americana de Historia Social, núm. 17, enero- junio 2021, pp. 198-128.

LEIDENBERGER, Georg. La historia viaja por tranvía. El transporte público y la cultura política de la ciudad de México. UAM, México, 2011.

LOAEZA, Soledad. Clases medias y política en México. La querella escolar, 1959-1963. México: Colmex, 1988.

MARCIAL AVEDAÑO, Armando D. Higiene y metrópoli en el gobierno de Álvaro Obregón. In: COLLADO, María del Carmen (Coord.). Miradas recurrentes 1. La ciudad de México en los siglos XIX y XX. Instituto Mora/UAM-A, México, 2004, pp. 333-348.

MASSEY, Doreen. Espacio, lugar y género, Gloria Elena Bernal (trad.). Debate Feminista, vol. 17, abril de 1998, pp. 39-46.

MASSEY, Doreen. Space, place and gender, Minneapolis, University of Minnesota Press, 1994.

NASAW, David. Children of the City at Work and at Play. Anchor Press, Doubleday, Nueva York, 1985.

OLSEN, Patrice Elizabeth. Un hogar para la revolución: patrones y significado del desarrollo residencial. In: COLLADO, María del Carmen (Coord.). Miradas recurrentes 1. La ciudad de México en los siglos XIX y XX. Instituto Mora/ UAM-A, México, 2004, pp. 132-165.

PADILLA ARROYO, Antonio et. al. (coords.). La infancia en los siglos XIX y XX. Discursos e imágenes, espacios y prácticos. UAEM/Casa Juan Pablos, México, 2008.

PICCATO, Pablo. Ciudad de sospechosos. Crimen en la Ciudad de México, 1900-1931. Lucía Rayas (trad.). CIESAS, México, 2010.

PORTER, Susie. Espacios burocráticos, normas de feminidad e identidad de la clase media en México durante la década de 1930. ACEVES, M. T. Fernández; ESCANDÓN, C. Ramos; 
Fronteiras - Revista Catarinense de História | https://periodicos.uffs.edu.br/index.php/FRCH/index ISSN 2238-9717 | n. 38, p. 189-219, jul.-dez./2021 | DOI: https://doi.org/10.29327/253484.1.38-12

PORTER, S. (Coords.). Orden social e identidad de género México, siglos XIX y XX (pp. 189-213). México: CIESAS/ Universidad de Guadalajara, 2006.

PORTER, Susie. From Angel to Office Worker: Middle-Class Identity and Female Consciousness in Mexico, 1890-1950.Lincoln: University of Nebraska Press, 2018.

PULIDO ESTEVA, Diego. ¡A su salud! Sociabilidades, libaciones y prácticas populares en la ciudad de México a principios del siglo XX. El Colegio de México, México, 2014.

RODRÍGUEZ, Kuri. La ciudad oficial, 1930-1970. In: KURI, Ariel Rodríguez. Historia política de la Ciudad de México. Desde su fundación hasta el año 2000. El Colegio de México, México, 212, pp. 417-482.

RODRÍGUEZ, Kuri. La experiencia olvidada. El ayuntamiento de México: política y gobierno, 1876-1912, El Colegio de México/UAM, México, 1996.

ROJAS SOSA, Odette María. "El bajo mundo del pecado". Vicio, crimen y bajos fondos en la ciudad de México, 1929-1944. In: GUERRA, Speckman; VASQUÉZ, Elisa y Fabiola Bailón (coords.). Vicio, prostitución y delito. Mujeres transgresoras en los siglos XIX y XX. UNAM, México, 2016, pp. 49-83.

SÁNCHEZ CALLEJA, María Eugenia. Niños y adolescentes en abandono moral. Ciudad de México (1864-1926), INAH, México, 2014.

SÁNCHEZ CALlEJA, María Eugenia; ANAYA, Delia Salazar. Los niños: su imagen en la historia. Instituto Nacional de Antropología e Historia, México, 2006.

SÁNCHEZ PARRA, Cristina; MATAMOROS, María Graciela León. El discreto encanto: distinción y diversión de las clases medias. Oficio, revista de Historia e Interdisciplina,núm. 10, enero-junio de 2020, pp. 5 y 6.

SÁNCHEZ PARRA, Jenny Cristina. Novedad y tradición. Las tiendas por departamentos en la ciudad de México y su influencia en el consumo, 1891-1915. Tesis de doctorado en Historia. El Colegio de México, 2017.

SILVA ESCOBAR, Juan Pablo. La Época de Oro del cine mexicano: la colonización de un imaginario social. Culturales, vol. VII, núm. 13, enero-junio 2011, pp. 7-30.

SOSENSKI, Susana. Diversiones malsanas: el cine y la infancia en la ciudad de México en la década de 1920. Secuencia. Revista de historia y ciencias sociales, n. 66, septiembre-diciembre 2006, pp. 37-64.

SOSENSKI, Susana. El día del niño en México: del festejo del trabajo a la fiesta de consumo (19201940). In: Infancias na História do Brasil e da América Latina, (seculo XX), 2018.

SOSENSKI, Susana. El niño consumidor: una construcción publicitaria de mediados del siglo XX. In: Ciudadanos inesperados. Espacios de formación de la ciudadanía ayer y hoy, El Colegio de México, México, 2012, pp. 191-222.

SOSENSKI, Susana. Niños en acción. El trabajo infantil en la ciudad de México 1920-1934. El Colegio de México, México, 2010.

SOSENSKI, Susana; JACKSON ALBARRÁN, Elena (Coords.). Nuevas miradas a la historia de la infancia en América Latina. Entre prácticas y representaciones, UNAM, México, 2012.

SOSENSKI, Susana; LEÓN, Ricardo López. La construcción visual de la felicidad y la convivencia familiar en México: los anuncios publicitarios en la prensa gráfica (1930-1970). Secuencia. Revista de historia y ciencias sociales, núm, 92, mayo-agosto de 2015, pp. 193-225.

STEARNS, Peter N. The Explosion of Consumerism in Western Europe and the United States. In: STEARNS, Peter N. Consumerism in World History. The Global Transformation of Desire, Rutledge, Nueva York, 2001, pp. 44-60. 
Fronteiras - Revista Catarinense de História | https://periodicos.uffs.edu.br/index.php/FRCH/index

ISSN 2238-9717 | n. 38, p. 189-219, jul.-dez./2021 | DOI: https://doi.org/10.29327/253484.1.38-12

TUÑón, Julia. Mujeres de luz y sombre en el cine mexicano. La construcción de una imagen, 1939-1952. El Colegio de México/IMCINE, México, 1998.

URÍAS HORCASITAS, Beatriz. El 'Hombre nuevo' de la posrevolución. Letras Libres, 31 de mayo de 2007. Disponible en: https://www.letraslibres.com/mexico/el-hombre-nuevo-laposrevolucion; acceso en: 30 de mayo de 2019.

VALENZUELA AGUILERA, Alfonso. Urbanistas y visionarios. La planeación de la Ciudad de México en la primera mitad del siglo XX. Porrúa, México, 2006.

\author{
Fuentes primarias \\ Boletín del Instituto Internacional Americano, Uruguay. \\ El plano regulador del Distrito Federal, México. \\ Planificación, México.
}

\author{
Hemerografía \\ La Prensa, Ciudad de México. \\ El Universal, Ciudad de México.
}

Recebido em 25/09/2021.

Aceito em 08/11/2021.

\footnotetext{
${ }^{1}$ Este trabajo fue presentado y comentado en el Seminario de la Ciudad de México. Pasado y presente organizado por el Instituto Mora, el día 24 de junio de 2021. Forma parte de la investigación realizada para obtener el grado de Maestra en Historia Moderna y Contemporánea por el Instituto Mora y como becaria del Centro Nacional de Ciencia y Tecnología.

${ }^{2}$ En México, resaltan algunos ejemplos que han sido sumamente importantes en la discusión de la historiografía de la infancia, como: Sosenski (2010); Sosenski y Albarrán (2012); Jackson (2014); Alcubierre (2010); Sánchez (2014); Sánchez y Salazar (2006); Del Castillo (2006); Padilla (2008); Rodríguez (2012);

${ }^{3}$ Algunos de los ejemplos más importantes de este debate historiográfico son: Aréchiga (2012; 2013); Barbosa (2018); Berra Stoppa (1981); Canto (2015); Leidenberger (2011); Marcial (2004); Rodríguez (2012); Piccato (2010); Pulido (2014); Rojas (2016). En México, resaltan algunos ejemplos que han sido sumamente importantes en la discusión de la historiografía de la infancia, como: Sosenski (2010); Sosenski y Albarrán (2012); Jackson (2014); Alcubierre (2010); Sánchez (2014); Sánchez y Salazar (2006); Del Castillo (2006); Padilla (2008). Véase: Barbosa (2008); Sosenski (2010).

${ }^{4}$ En México, ha surgido una línea historiográfica que discute al respecto a partir de dos elementos específicamente: por un lado, la burocracia y, por el otro, la educación. También se ha abordado desde el lugar que se ocupa en el espacio urbano. En ese sentido, es importante notar que se ha analizado el papel de los empleados públicos entre finales del siglo XIX e inicios del XX como uno de los grupos a los que se les podría vincular con la clase media. Con respecto a la educación, se ha planteado que su acceso ha representado la posibilidad de ascenso social de las clases más pobres. Finalmente, la clase media aparece en la actualidad para ser discutida a partir de distintas perspectivas, de entre las que destacan las prácticas de consumo y culturales. Véase: Barbosa (2020); Barbosa (2013); Porter (2006); Porter (2018); Loaeza (1988); Sánchez y León (2020).

${ }^{5}$ Estos cambios ocurridos entre finales del siglo XIX e inicios del XX en la infraestructura escolar, pueden ser estudiados en Chaoul (2014).

${ }^{6}$ Esta frase hace alusión a la mencionada por Erica Berra Stoppa: "La Revolución Mexicana proyectó un modelo en que las ciudades serán los centros fundamentales de la vida regional y la ciudad de México, por ende, el corazón del conjunto del proyecto nacional", (BERRA, 1982, p. XV).
} 
Fronteiras - Revista Catarinense de História | https://periodicos.uffs.edu.br/index.php/FRCH/index

ISSN 2238-9717 | n. 38, p. 189-219, jul.-dez./2021 | DOI: https://doi.org/10.29327/253484.1.38-12

${ }^{7}$ Como lo ha demostrado la historiografía, muchas veces esto no fue más que un sueño, dado que los sectores populares no siempre mejoraron sus condiciones de trabajo y de vivienda en el Distrito Federal. Para un análisis al respecto, aunque no centrado en el Distrito Federal, véase: Aboites y Loyo (2011, pp. 619-616).

${ }^{8}$ Véase: Olsen (2004).

${ }^{9}$ El cual consistió, entre otros factores, en demandar la falta de servicios públicos en las viviendas y el alza de precios de alquileres. Véase: Ávila (2017); Berra (1981); Durand (1989); Grant (2010).

${ }^{10}$ Carlos Contreras fue un arquitecto nacido en Aguascalientes en 1892. Estudió en la Universidad de Columbia en Nueva York donde aprendió algunos de los principios urbanísticos más importantes de inicios del siglo XX, los cuales buscó aplicar en México. Fue parte de las instituciones más relevantes de planeación urbana en el periodo que se estudia en este trabajo.

${ }^{11}$ Para comprender el proceso de transformación urbana a partir de la industrialización, véase: Harvey (1992); Massey (1994).

${ }^{12}$ Según cifras de la autora, para 1911 se calculaban 6364 vehículos circulando en el país; 13450 en 1924 y 40000 en 1929.

13 "Mensaje del presidente de la república a la nación", El Universal, 1 de enero de 1934, secc. 2, pp. 10 y 11.

${ }^{14}$ Los niños estaban presentes en la capital. Para la década de los treinta, en el Distrito Federal había 251229 niños que se encontraban en un rango de cinco a catorce años. Cifra que correspondía al 19\% de la población. Para la década de los cuarenta, el número era mayor: 396254 menores; es decir, el 22\% de la población. En términos relativos, el porcentaje de niños en el DF era parecido al del resto de la república, el cual era del $24 \%$ para los años treinta y $27 \%$ de la población, una década después. En 1930 el 1\% de los niños de la república mexicana habitaba en el DF y, para 1940, el 2 por ciento, véase: Censo General de Población, años 1930 y 1940. Véase: Berra (1982).

${ }^{15}$ Claramente, en los niños no se enfocaron las acciones ni el presupuesto gubernamental; no obstante, aunque sin coordinación interinstitucional, se diseñó un sistema para su atención, el cual, al menos desde la planeación, promovía una transformación de la infancia después de la revolución.

${ }^{16}$ Inicialmente, la revista Planificación estuvo a cargo del arquitecto Carlos Contreras, al final, el ingeniero Enrique E. Schultz. Fue publicada de entre 1927 y 1936 con el fin de abordar las ideas con respecto a la racionalización y mejoramiento de las ciudades.

${ }^{17}$ Es interesante notar que desde el discurso de la planeación urbana ya se daba cuenta de que la experiencia de las niñas y los niños en el espacio público sería distinta. A las niñas, se les seguía vinculado con el espacio doméstico y con una dinámica de movilidad mucho más acotada.

${ }^{18}$ Se trata de lo que hoy conocemos como Parque Hundido.

19 "Embellecimiento de la Ciudad de México", La Prensa, 11 de agosto de 1940, p. 9.

${ }^{20}$ La noción de "hombre nuevo" se ha abordado en la historiografía y en los medios de la época de manera profusa. Se trata de una categoría de enunciación diversa que se puede encontrar en múltiples escenarios y países, para el caso de esta investigación se entiende que se está construyendo a partir de una serie de políticas y reglamentaciones con respecto a la higiene, la escolarización y la recreación que incluía a niños y niñas. Se trataba de un concepto que buscaba alcanzarse a través de la práctica. Para un análisis breve, pero de largo alcance, véase: Beatriz Urías Horcasitas, "El 'Hombre nuevo' de la posrevolución", en Letras Libres, 31 de mayo de 2007, <https://www.letraslibres.com/mexico/el-hombre-nuevo-la-posrevolucion>, [Consultada: 30 de mayo de 2019]

${ }^{21}$ Por ello, la educación física comenzó a ser un ámbito importante en la educación de los infantes a inicios del siglo XX. Ezequiel Padilla, Secretario de Educación Pública entre 1928 y 1930 declaraba lo siguiente que era "necesario contar con el hombre física, intelectual, cívica y patrióticamente", "La educación física en México", Boletín del Instituto Internacional Americano, tomo IV, núm. 1, julio de 1930, p. 120.

${ }^{22}$ Para conocer más del tema en la infancia porpular, véase: Sosenski (2010); Lechuga (2021).

${ }^{23}$ Es importante mencionar que se revisó un mes por año del periódico El Universal durante la década del treinta para poder hacer esta afirmación.

${ }^{24}$ A pesar de que la festividad del día del niño quedó instaurada en el año de 1935, como lo puntualizó Susana Sonsenski, en sus inicios no implicó la compra de regalos para los infantes. Es probable que como la autora indica, haya sido ya hasta entrada la década del cuarenta que aumentó el número de anuncios relacionados con el día del niño, véase: Sosenski, 2018. Después de la revisión hemerográfica realizada para esta investigación, se constató que la mayor parte de la publicidad de juguetes estaba concentrada en los primeros días de enero y no durante el mes de abril.

25 "Niños de ahora", El Universal, 6 de enero de 1934, p. 5.

${ }^{26}$ Véase: Stearns (2001); Leach (1994).

${ }^{27}$ Véase: Nasaw (1985). 
Fronteiras - Revista Catarinense de História | https://periodicos.uffs.edu.br/index.php/FRCH/index

ISSN 2238-9717 | n. 38, p. 189-219, jul.-dez./2021 | DOI: https://doi.org/10.29327/253484.1.38-12

${ }^{28}$ [Traducción propia]

${ }^{29}$ Susana Sosenski explica que el niño consumidor fue aludido desde el siglo XIX; sin embargo, se convirtió en un agente en el mercado, como tal, hasta la década de los cincuenta del siglo XX. Véase: Sosenski, 2012.

${ }^{30}$ Estadísticas históricas de México, México, INEGI, 1999, tomo I, p. 17.

${ }^{31}$ Como lo ha puntualizado Susana Sosenski en Niños en acción, 2010, muchos de los niños trabajadores circularon por el centro de la ciudad. Es probable que algunos de ellos hubieran podido ver los juguetes, aunque no comprar, evidentemente. Esto no significa que no tuvieran acceso a estos artículos, dado que muchas instituciones de asistencia pública entregaban juguetes a este sector durante el día de reyes.

32 "Exposición de juguetes", El Universal, 20 de diciembre de 1935, sec. 2, p. 8.

33 "Bicicletas", El Universal, 3 de enero de 1934, sec. 2, p. 5.

${ }^{34}$ Se entiende por teatro guiñol a aquel en el que se hacen representaciones teatrales por medio de títeres y marionetas. En el contexto de la época, se presentaba en carpas y con escenarios hechos con madera que se podían trasladar de un lugar otro.

${ }^{35}$ Incluso podría pensarse que el teatro guiñol puede ser visto como parte de la estrategia de articular el DF a partir de la cultura y, también, de un sistema integral de atención a la infancia.

36 "Pinocho llega al "Arbeu", El Universal, 9 de septiembre de 1937, p. 11.

37 "Pinocho llega al "Arbeu", El Universal, 9 de septiembre de 1937, p. 11.

${ }^{38}$ Se debe tomar en cuenta que el costo del pasaje dentro de la ciudad en 1930 era de 2.72 pesos y en 1935 de 2.51 pesos. Véase: Bayardo (2018, p. 121).

${ }^{39}$ La mayor parte de la cartelera del cine estaba ocupada por películas extranjeras, básicamente estadounidenses.

40 "Los niños que van al cine", El Universal, 6 de septiembre de 1937, p. 1.

41 "Los niños que van al cine", El Universal, 6 de septiembre de 1937, p. 1.

42 "Los niños que van al cine", El Universal, 6 de septiembre de 1937, p. 4.

${ }^{43}$ De acuerdo con el material hemerográfico revisado, y aunque no es el propósito hacer un análisis de los precios del cine, sí se puede identificar a simple vista que éstos se fueron incrementando con el paso de los años.

44 "Cine gratis", La Prensa, 2 de agosto de 1940, p. 20.

${ }^{45}$ Se refiere al periodo comprendido entre 1936 y 1956 en el que el cine mexicano alcanzó su mayor esplendor.

46 "El gusto por el cine se incrementa: en 1934, de 52 millones de localidades vendidas en cines, teatros, plazas de toros, palenques, centros deportivos y carpas, $70.1 \%$ corresponde a los que asisten al cine y le sigue, con $22.5 \%$, el teatro. En 1947, de 115 millones de localidades, $92.4 \%$ corresponde al cine y sólo $1.7 \%$ al teatro. El cine crece aparentemente a expensas del teatro y la carta y muy ligado en sus contenidos a éstos. Aparece también muy ligado a la radio", (TUÑÓN, 1998, p. 52).

${ }^{47}$ El Universal, 10 de enero de 1934, p. 6. 